\title{
Frictional stress analysis of spur gear with misalignments
}

\author{
Jason Eng ${ }^{1}$, Saravanan Karuppanan ${ }^{1}$ and Santosh Patil ${ }^{2 *}$ \\ ${ }^{1}$ Mechanical Engineering Department, Universiti Teknologi PETRONAS, \\ 32610 Bandar Seri Iskandar, Perak, Malaysia. \\ ${ }^{2}$ Mechanical Engineering Department, Manipal University Jaipur, \\ 303007, Jaipur, Rajasthan, India. \\ *Email: santosh045@gmail.com
}

\begin{abstract}
Misalignments in gears cause vibrations and contact nonlinearities, which in turn cause load distribution shift on the gear tooth. The load distribution shift of the gear pair results in increased contact and bending stresses with the maximum stresses leaning towards the edge of the face width. These stress changes cause failures and gear performance variations, such as pitting, scuffing, crack initiation and eventually tooth breakage. In this paper, the contact and bending stresses of a misaligned spur gear pair were evaluated with and without friction by employing corresponding analytical methods and finite element method (FEM). Friction coefficient values of 0.1 to 0.3 were used to evaluate the effects of friction on contact and bending stress distribution of a spur gear pair with axial and angular misalignments. The stress concentration was found to be higher at the contact point and at the tooth root of the gear with the augmentation of the misalignment distance and angle. The maximum contact and bending stresses increased by $67.5 \%$ and $18.9 \%$, respectively, when axial misalignments were subjected. Similarly, the maximum contact and bending stresses increased by $27.0 \%$ and $62.4 \%$, respectively, for angular misalignments. Furthermore, the contact and bending stresses increased proportionally with the increasing coefficient of friction. Finally, the relationships between the normalized stress and misalignments (both axial and angular) were established.
\end{abstract}

Keywords: Misalignment; spur gear; contact stress; bending stress; FE analysis; friction.

\section{INTRODUCTION}

Misalignments in gears are considered as one of the major contributing factors for increased stress concentrations at specific locations of the gear tooth $[1,2]$. The stress concentration region is the initiation point of a failure or fracture of the gear tooth [3]. Several recent researches [4-7] have concentrated on using the FE approach to determine the stress concentrations on the spur gear tooth. Hassan [4] developed a program which uses superposition mode calculation of meshing teeth to determine the contact stresses. The results were compared to results obtained using FE approach for validation. The results agree well which indicates the reliability of both methods. Contact stress and its behavior is very important in the evaluation of pitting and surface failure [5]. The stress 
concentrations generated due to misalignments influence the gear tooth contact stresses significantly. Hence the study of the effects of misalignments on gear contact stresses is important. In gear contact, the gear misalignments imply the axial shift in position of the mating surfaces due to deflections or errors in manufacturing of the gear and their housing [8]. Gear misalignment is considered as one of the most common repeated problems in most rotating machineries [9]. The main causes of misalignments on the gear are lead slope errors, lead wobble, bore parallelism and shaft bending deflections. Several studies and researches have been conducted and different methods have been used for the stress analysis on the misaligned gear teeth [8]. Bommisetty [10] elaborated on three types of misalignments in a gear shaft which are parallel misalignments, angular misalignments parallel to the plane of action and angular misalignment perpendicular to the plane of action. Lias et al. [1] conducted a study on the stress distribution of gear subjected to the axial misalignment condition. They found that the equivalent stresses at the root increased almost twice as the equivalent stresses at the contact region. The stress concentration was found to have increased proportionally to the misalignment angle at the contact region and at the tooth root. Bending stress analysis is also an important objective of static performance investigation because it is the primary reason of various gear tooth failures. Bending stress is investigated in similar fashion to that of a contact stress investigation. The only difference between the two is that the bending stress depends on the gear tooth geometry compared to contact pressure which is much straight forward [11-12]. Prabhakaran et al. [13] evaluated the bending stress on the spur gear tooth with angular misalignments and discovered that the bending stress and load distribution factor increases with the increasing misalignment angle. The load is assumed to be uniform when the gear contact is aligned as shown in Figure 1(a) but when misalignment occurs the load will be shifted to the gear tooth flank as shown in Figure 1(b).
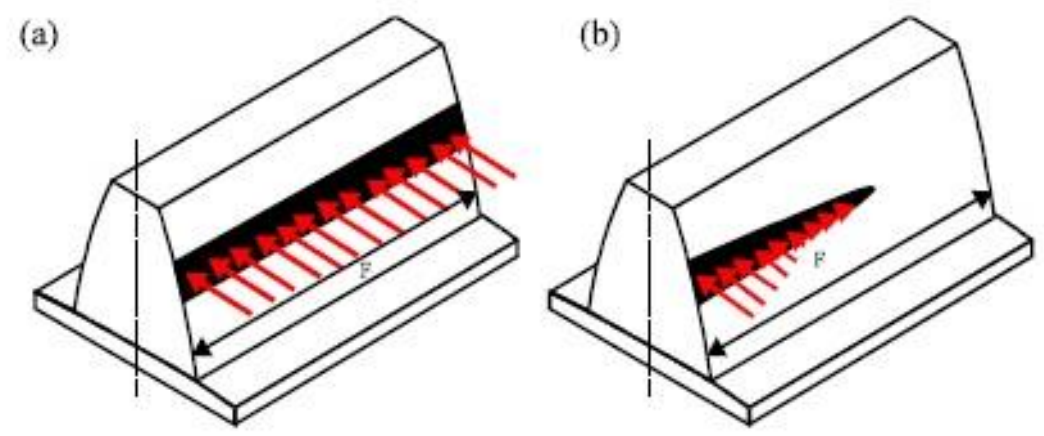

Figure 1. The load distribution on spur gear tooth surface (a) aligned condition; (b) misaligned condition [1].

Normally, contact phenomena always involves friction. Friction between the gear contacts affects contact and bending stresses differently, making the evaluation complex and nonlinear. Farhan et al. [14] conducted a study on how friction affects the contact stresses using numerical methods. The study showed that the contact stresses increased in the range of $10 \%$ as the frictional coefficients were increased from 0 to 0.3 . Refaat and Meguid [15] presented a study on the implementation and development of a new mathematical and reliable method for the analysis of contact stresses on spur gears. The method involved solving of variational inequalities representing the general contact 
problem in spur gears and also considering the effects of friction on the contact stresses. Patil et al. [16] discovered that frictional variations affect the point of contact and cause deviations in maximum pressure values. Zheng Li and Ken Mao [17] investigated the effects of friction towards the gear tooth contact analysis and discovered that transmission error is an excitation mechanism which causes gear noise and vibration due to friction. The effects of friction depend on the coefficient of friction of contact surfaces and the torque applied. In actual design and manufacturing processes, the friction and deformation will exist and cannot be eliminated completely. Therefore, this paper aims to investigate the effects of axial and angular misalignment, including friction towards the evaluation of contact and bending stresses of the spur gear.

\section{METHODOLOGY}

\section{Analytical Approach}

The contact and bending stresses of the gear were determined using the Hertz theory [4] of contact stresses and Lewis equation [18], respectively. These stresses were also evaluated analytically by using their corresponding American Gear Manufacturers Association (AGMA) standard equations. A spur gear pair was chosen, consisting of a pinion and a gear for the present study. The gear specifications for the pinion and gear are as listed in Table 1. The gear material properties are represented in Table 2.

Table 1. Specifications of pinion and gear used in the study.

\begin{tabular}{clc}
\hline No & Parameters & Pinion/Gear \\
\hline 1 & Centre Distance, $a$ & $101.6 \mathrm{~mm}$ \\
2 & Normal Pressure angle, $\phi$ & $20^{\circ}$ \\
3 & Module, $m$ & $5 \mathrm{~mm}$ \\
4 & Base Diameter, $d_{b}$ & $98.36 \mathrm{~mm}$ \\
5 & Number of Teeth, $N$ & 20 \\
6 & Face Width, $b$ & $25.4 \mathrm{~mm}$ \\
7 & Pitch Diameter, $P_{d}$ & $101.6 \mathrm{~mm}$ \\
8 & Outside Diameter, $d_{o}$ & $111.76 \mathrm{~mm}$ \\
9 & Addendum radius, $a$ & $5.08 \mathrm{~mm}$ \\
10 & Dedendum radius, $b$ & $5.87 \mathrm{~mm}$ \\
11 & Working Depth, $D$ & $10.16 \mathrm{~mm}$ \\
12 & Angular thickness, $t_{a}$ & $9 \mathrm{~mm}$ \\
\hline
\end{tabular}

Table 2. Material properties of pinion and gear used in the study.

\begin{tabular}{cc}
\hline Description & Pinion/Gear \\
\hline Material & SAE 2340 \\
Young's Modulus, $E$ & $200 \mathrm{GPa}$ \\
Poisson Ratio & 0.3 \\
Density & $7850 \mathrm{~kg} / \mathrm{m}^{3}$ \\
Thermal expansion & $11 \times 10^{-6}{ }^{\circ} \mathrm{C}$ \\
\hline
\end{tabular}

\section{Contact stress}

The contact stress of the gear set can be determined by the Hertz contact stress equation (as shown in Equation 1). 


$$
\sigma=\sqrt{\frac{F_{T}\left(1+\frac{r_{p 1}}{r_{p 2}}\right)}{r_{p 1} b \pi\left[\frac{\left(1-v_{1}^{2}\right)}{E_{1}}+\frac{\left(1-v_{2}^{2}\right)}{E_{2}}\right] \sin \emptyset}}
$$

where $F_{T}, b, \phi, v_{1}, v_{2}, r_{p 1}, r_{p 2}, E_{1}$ and $E_{2}$ are the load, face width, pressure angle, Poisson's ratio of pinion, Poisson's ratio of gear, pitch radius of pinion, pitch radius of gear, Young's modulus of the pinion and Young's modulus of the gear, respectively. The contact stress of the gear pair can also be calculated using the AGMA contact stress equation (Equation 2 ). The AGMA contact stress equation is based on Hertzian theory and it includes various correction factors.

$$
\sigma=Z_{e} \sqrt{F_{T} K_{0} K_{V} K_{S} \frac{K_{H}}{2 r_{p 1} b Z_{1}}}
$$

where $Z_{e}, F_{T}, K_{o}, K_{v}, K_{S}, K_{H}, b, r_{p 1}, Z_{1}$ are coefficient factor, load, overload factor, dynamic factor, size factor, load distribution factor, face width, pinions pitch radius and geometry factor for pitting resistance, respectively. The AGMA standards parameters for the pinion are listed in Table 3. The values for the coefficient factors were obtained from the AGMA Elastic coefficient [19]. As the gear was assumed to be a uniform operating machine, the overload factor was retrieved from operating characteristic of driving machines. The dynamic factor was obtained from the dynamic factor curve. The geometry factor for pitting resistance was selected for gear of 20 teeth. The size factor and load distribution factor were assumed to be 1 for optimum gear and evenly distributed load on the face width.

Table 3. Values of the parameters from AGMA standards used for the calculations

\begin{tabular}{cc}
\hline Parameter & Value \\
\hline$Z_{e}$ & $191 \mathrm{MPa}$ \\
$K_{o}$ & 1.0 \\
$K_{v}$ & 1.0 \\
$K_{S}$ & 1.0 \\
$K_{H}$ & 1.0 \\
$K_{B}$ & 1.1 \\
$r_{p}$ & $63.5 \mathrm{~mm}$ \\
$M$ & $6.35 \mathrm{~mm}$ \\
$Z_{1}$ & 0.32 \\
$Y$ & 0.32 \\
$F_{T}$ & $9000 \mathrm{~N}$ \\
\hline
\end{tabular}

\section{Bending stress}

The bending stresses on a typical gear tooth are mainly due to the tangential force components acting on the tooth. Based on Wilfred Lewis's assumptions of modelling a gear tooth as a cantilever beam [18], the bending stress can be calculated using the Lewis equation:

$$
\sigma_{b}=\frac{F_{t}}{b m Y}
$$


where $\sigma_{b}, F_{t}, b, m$, and $Y$ are the bending stress in gear tooth, tangential tooth load, face width, module and Lewis form factor, respectively. Design factors such as overload factor, dynamic load factor, size factor, load distribution factor, and rim thickness factor were introduced by the AGMA to estimate the bending stresses for practical design considerations. The values of the parameters are stated in Table 3.

$$
\sigma_{b}=\frac{F_{t}}{b m Y}\left(K_{0} K_{v} K_{S} K_{H} K_{B}\right)
$$

where $K_{o}, K_{v}, K_{S}, K_{H}$ and $K_{B}$ are overload factor, dynamic factor, size factor, load distribution factor and rim thickness factor, respectively.

\section{Gear Analysis Using ANSYS}

The spur gear model consisting of the gear and pinion was modelled and assembled using SolidWorks 2015. The model was than saved in IGES format so that the model can be imported into ANSYS 15 with least/no data loss. ANSYS Workbench platform was used for the static structural analysis of the spur gear model. The assembled model imported into ANSYS Workbench is represented in Figure 2. The model was then meshed accordingly to discretize the geometry for further analysis. Proper meshing provides better approximations and yield reliable results, which will be close to exact solutions. Initially, mesh convergence test was conducted on the constructed model. To perform mesh convergence, the model was initially subjected to coarse mesh and subsequently mesh size was reduced. An iteratively analysis was then carried out until results show minimal changes between iterations. The results were computed by solving the relevant governing equations numerically at the nodes of the mesh. The optimum mesh size was selected based on factors such as time constraint and also performance of the computer. The mesh sizing inserted at the contact point was set at $0.0254 \mathrm{~mm}$ based on the mesh convergence test. Edge sizing function was used on the edges where the tooth was in contact. Fine mesh was applied to the contacting edge only, because it was not practical to use fine mesh on the entire model. The mesh type assigned for this model was quadtype, as it would provide appropriate results with better interpolation. The number of elements was 66060 and the number of nodes was 359340. Figure 3 shows the meshed model of the spur gear set.

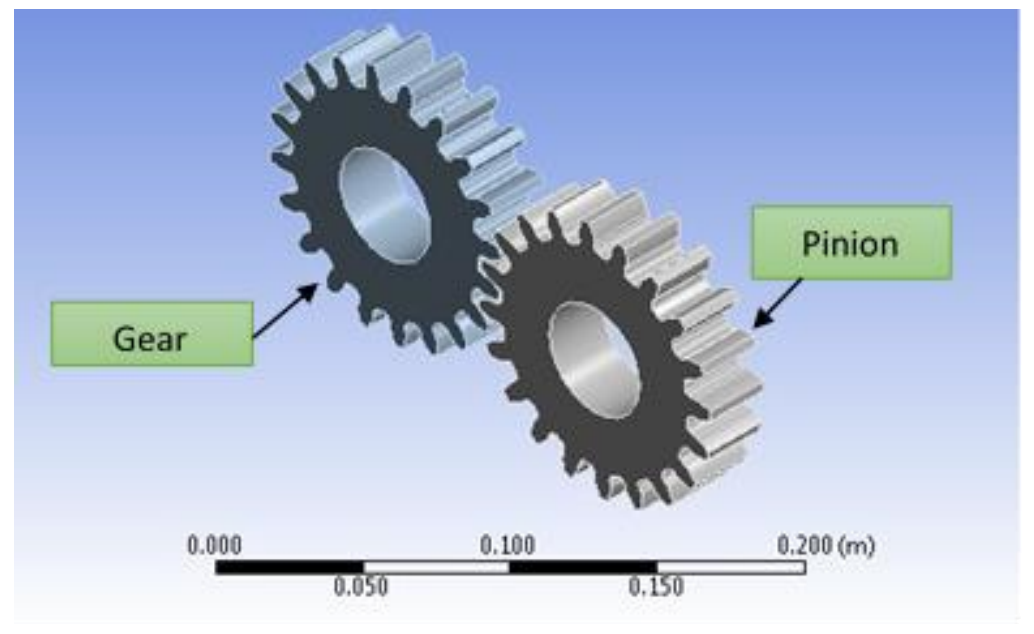


Figure 2. Spur gear pair assembly.

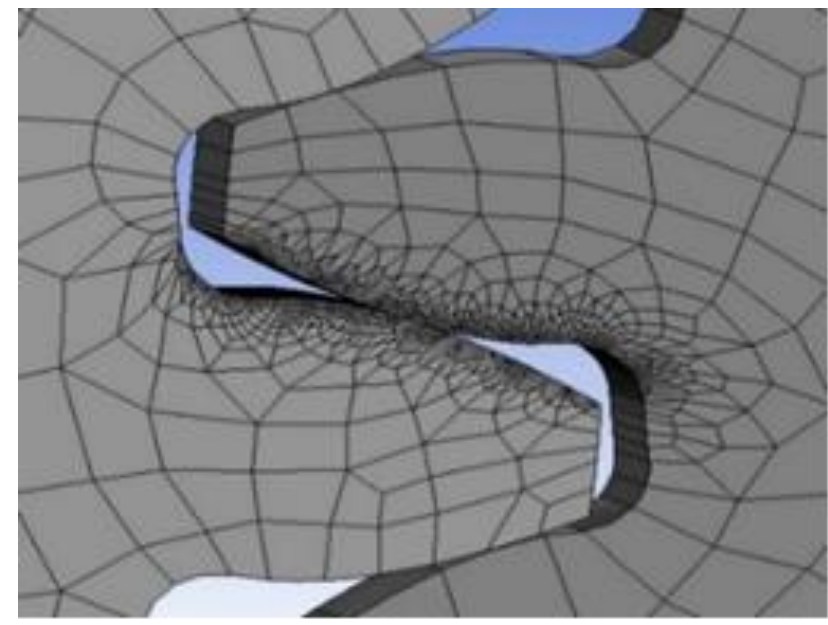

Figure 3. Fine quad-type meshed model at the gear contacting point.

The contact type and region of the spur gear were specified to their appropriate contact surfaces. There are several types of contacts available in the ANSYS Workbench, such as bonded, separation, frictionless, rough and frictional. A frictionless contact type was selected for the ideal case or the validation case of the model. Frictional contact was defined to simulate the contact and bending stresses of the spur gear set under different coefficient of friction.

In order to simulate a rotating gear set, the boundary conditions were defined for the spur gear pair. The centre distance between the gear and pinion was $101.6 \mathrm{~mm}$. The fixed and frictionless supports were defined at the gear and pinion area labelled A and B, respectively, as shown in Figure 4. When the fixed and frictionless supports were defined, one gear will be driving the other gear and the simulation of a rotating gear set can be conducted. A typical moment value of $500 \mathrm{Nm}$ was applied on the gear which will induce a rotational motion at the $\mathrm{Z}$-axis.

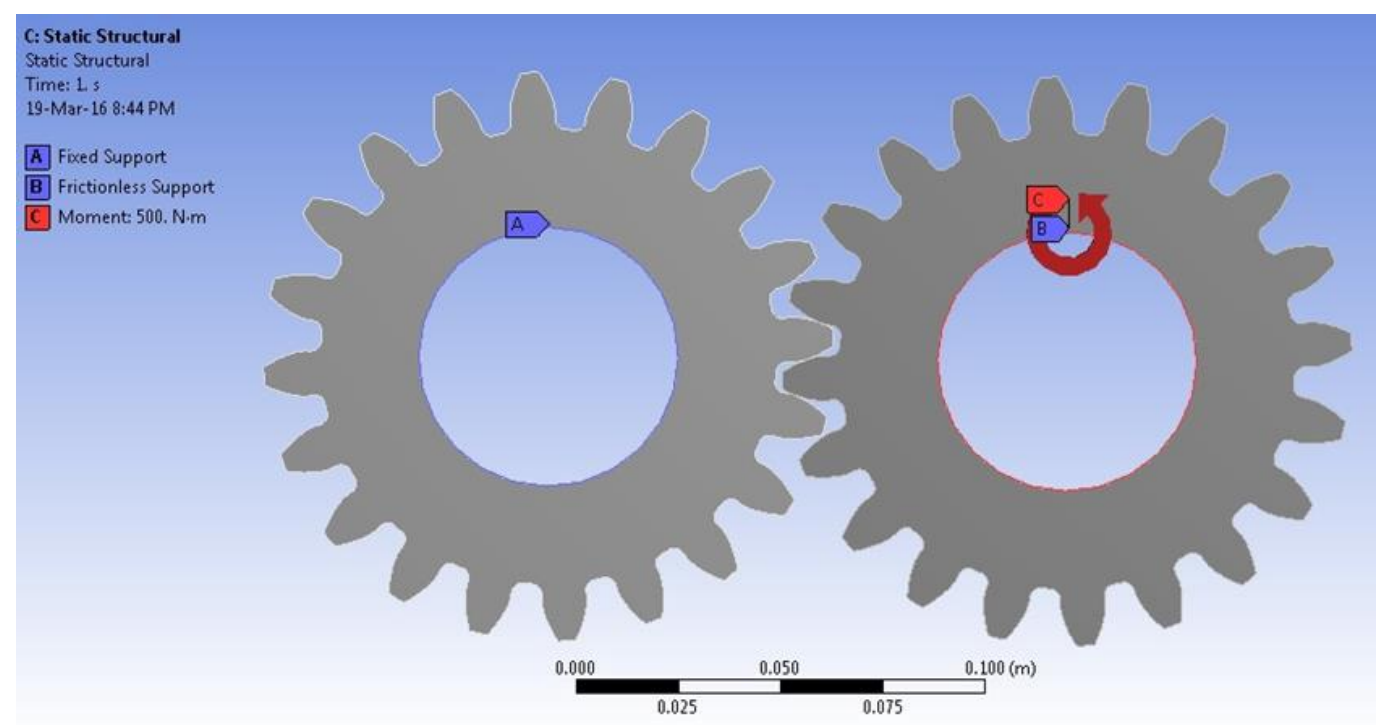


Figure 4. Gear boundary conditions.

After the mesh was generated and the contact point was defined along with the other boundary conditions (pre-processor), the solution can be obtained by solving the model (solver). In the post-processor, the results were recorded as per requirement. The results obtained from the frictionless contact stress simulation were then compared to the analytical methods. The analysis for frictional contact and bending stresses were also performed which include misalignment. Both axial and angular types of misalignments have been focused in the present study.

\section{Axial and angular misalignment (frictional)}

The model was misaligned axially in the negative z-direction and frictional contact was defined to evaluate the effects of misalignment to the contact and bending stresses with friction. The gear pair was subjected to parallel misalignment that ranged from $1 \mathrm{~mm}$ to $5 \mathrm{~mm}$, which are the typical values in gearing. Figure 5a shows the gear pair subjected to an axial misalignment.

The gear model was subjected to angular misalignment parallel to the plane of action. The gear model was rotated along the y-axis at misalignment angles ranging from $0.5^{\circ}$ to $2^{\circ}$, which are the typical values in gearing, prior to the evaluation of contact and bending stresses on gear pair subjected to angular misalignments. Similarly, frictional contact was defined to evaluate the frictional effects to the contact and bending stresses of the gear pair. Figure $5 \mathrm{~b}$ shows the contact point of the gear pair subjected to angular misalignment.
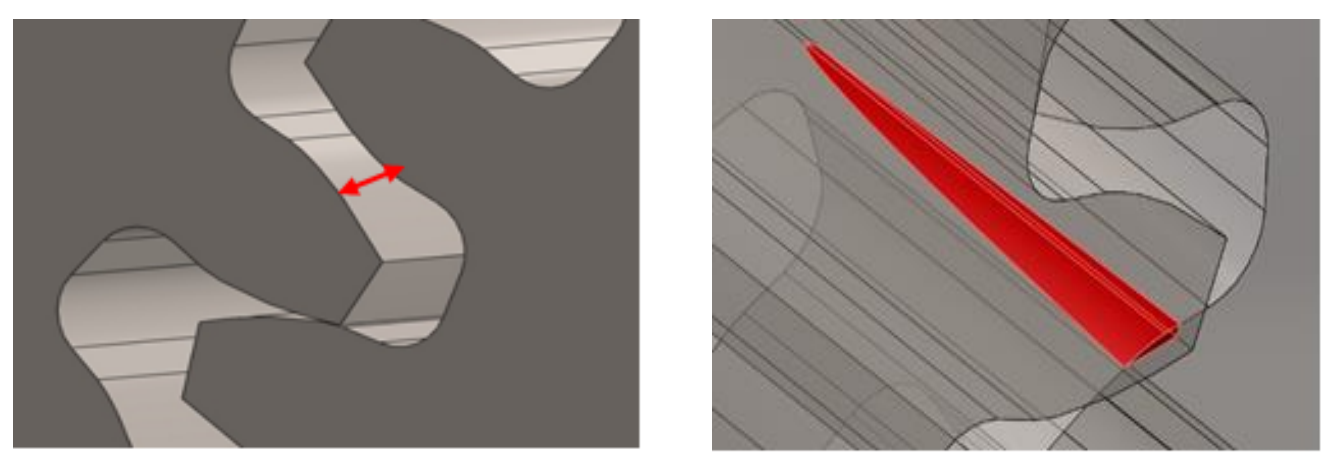

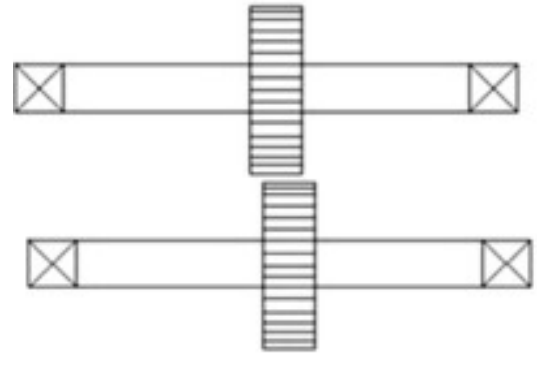

(a)

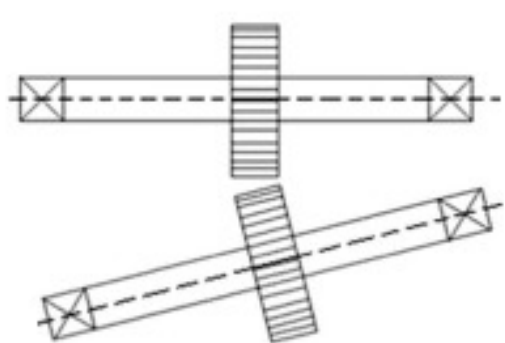

(b)

Figure 5. Gear misalignment (a) axial (b) angular. 


\section{RESULTS AND DISCUSSION}

\section{Validation of FEA results}

The finite element model generated was used to evaluate the contact and bending stresses of the spur gear. Figure 6 shows the maximum contact stress regions of the meshing gear tooth without friction and misalignments. Prior to extensive simulation of gear models, FEA results were validated with analytical analyses which were based on Hertz contact stress theory, Lewis equation and AGMA standards. The results for contact and bending stresses obtained from the numerical methods and analytical equations were compared and the maximum percentage difference between them was calculated. Table 4 shows the contact stress comparison obtained from FEA using ANSYS 15, Hertz equations and AGMA standards.

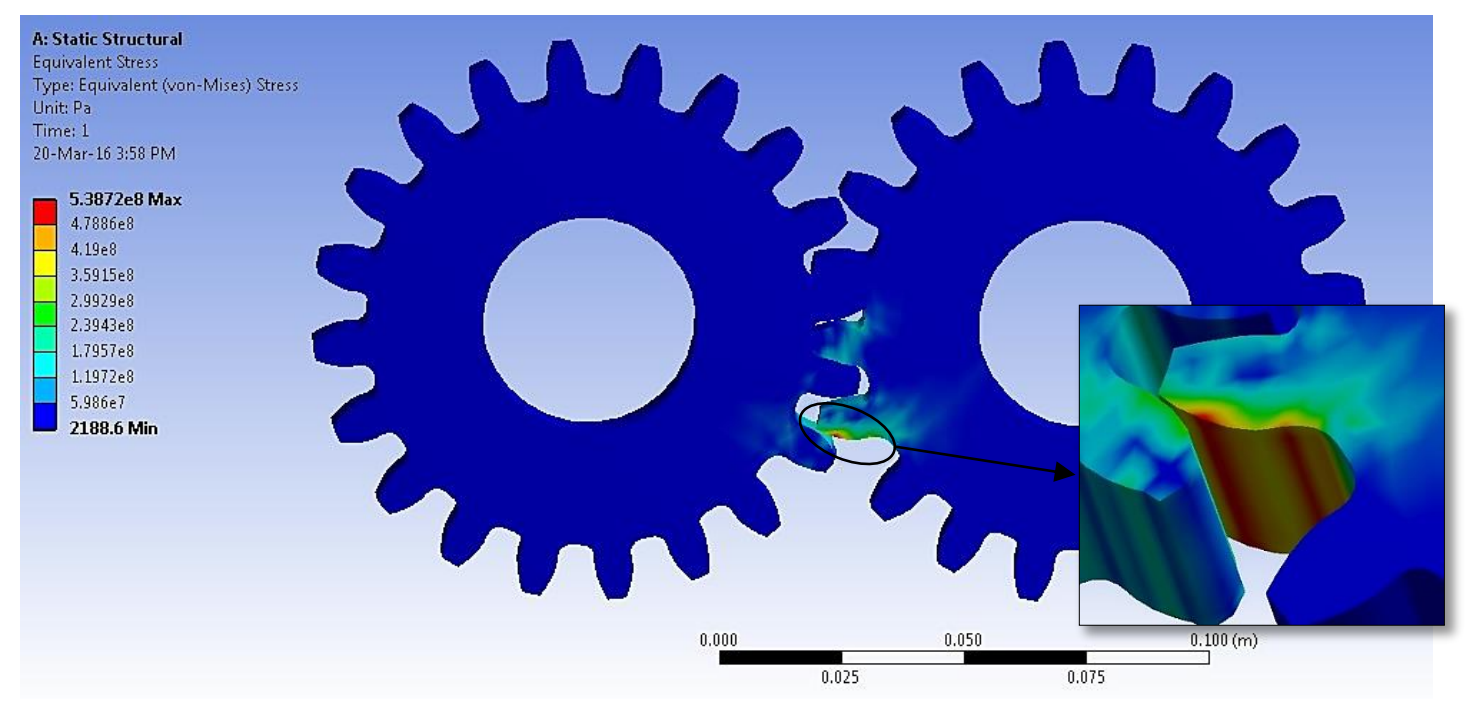

Figure 6. Equivalent von Mises stress distribution on the gear tooth.

Table 4. Comparison of von Mises equivalent contact stresses determined using FEA method, Hertz equation and AGMA standards.

\begin{tabular}{cccc}
\hline $\begin{array}{c}\text { FEA } \\
(\mathrm{MPa})\end{array}$ & $\begin{array}{c}\text { Hertz Theory } \\
(\mathrm{MPa})\end{array}$ & $\begin{array}{c}\text { AGMA Standards } \\
(\mathrm{MPa})\end{array}$ & $\begin{array}{c}\text { Maximum } \\
\text { percentage } \\
\text { difference }(\%)\end{array}$ \\
\hline 364.2 & 376.6 & 380.5 & 4.28 \\
\hline
\end{tabular}

The maximum percentage difference of $4.28 \%$ was found between FE results and AGMA standards. The values obtained from the AGMA standards were higher compared to Hertz's equation as more design/correction factors such as overload factor, dynamic factor, size factor and load distribution factor were taken into consideration. The results obtained from ANSYS were validated as the percentage differences compared to analytical calculations ranged from $3 \%$ to $5 \%$ and show good level of agreement. Further, the bending stresses were evaluated both analytically and by using finite element method. Table 5 shows the von Mises bending stress comparison obtained from FEA using ANSYS 15, Lewis equation and AGMA standards. 
Table 5. Comparison of von Mises bending stresses determined using FEA method, Lewis equation and AGMA standards.

\begin{tabular}{cccc}
\hline $\begin{array}{c}\text { FEA } \\
(\mathrm{MPa})\end{array}$ & $\begin{array}{c}\text { Lewis Equation } \\
(\mathrm{MPa})\end{array}$ & $\begin{array}{c}\text { AGMA Standards } \\
(\mathrm{MPa})\end{array}$ & $\begin{array}{c}\text { Maximum } \\
\text { percentage } \\
\text { difference }(\%)\end{array}$ \\
\hline 319.9 & 333.3 & 352.4 & 9.24 \\
\hline
\end{tabular}

The maximum percentage difference of $9.24 \%$ was found between FE results and AGMA standards. The results obtained from ANSYS were validated as the percentage differences compared to analytical calculations were below $10 \%$ and hence showing an agreeable match between the two methods.

\section{Finite element analysis with misalignments}

\section{Results for axial misalignment}

The contact stress values with and without axial misalignments were evaluated in order to study the effects of axial misalignments on the contact stresses of the gears. The gears were subjected to axial misalignment ranging from $1 \mathrm{~mm}$ to $5 \mathrm{~mm}$, the typical misalignment values and the maximum stresses were recorded. In addition, the friction condition was included to simulate the effects of friction towards the stresses. Relationships between the contact stress against axial misalignment distance and bending stress against axial misalignment distance were generated. Figure 7 shows the sample stress distribution with misalignment, where the equivalent stress has been shifted towards the edge of gear tooth flank. The shift in the loading due to misalignment has caused this uneven stress distribution towards the edge.

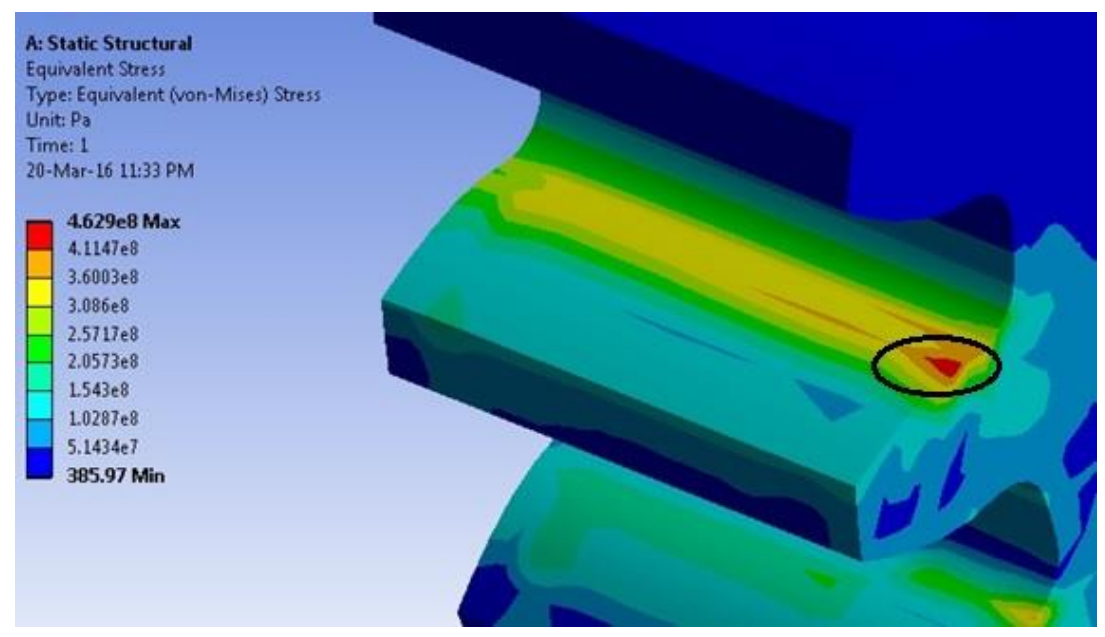

Figure 7. Maximum contact stress at the edge of gear tooth due to misalignment. 


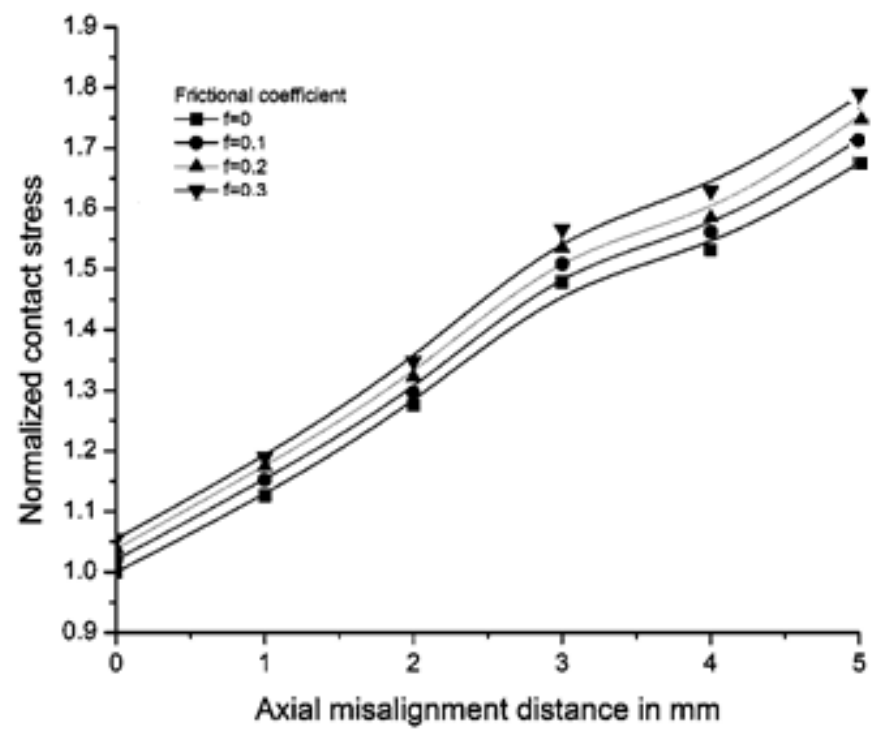

Figure 8. Maximum contact stress at the edge of gear tooth due to misalignment.

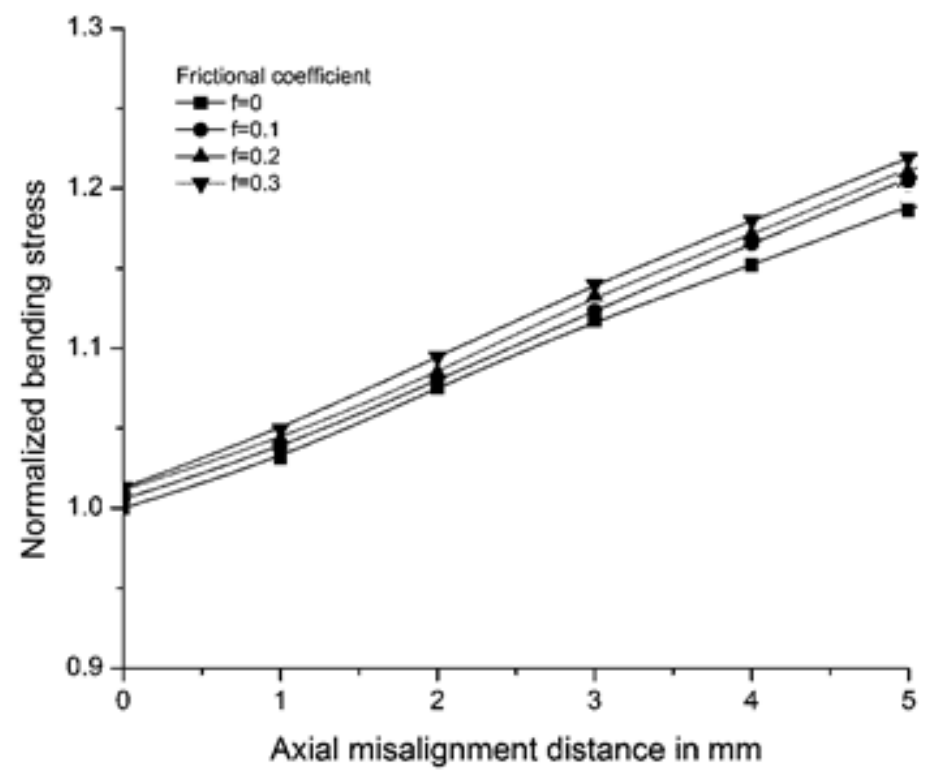

Figure 9. Maximum bending stress at the root of gear tooth due to misalignment

Figure 8 shows the relationship between the normalized contact stress, $\left(\frac{\sigma_{c \text { axl }}}{\sigma_{\text {ideal }}}\right)$ and the axial misalignment, where the contact stress increases proportionally with increasing axial misalignment distance. The maximum contact stress values were found at the gear contact point. It was observed that the highest contact stress values occurred during the largest misalignment distance of $5 \mathrm{~mm}$. The maximum contact stress increased by approximately $67.5 \%$ when the axial misalignment distance was increased from $0 \mathrm{~mm}$ to $5 \mathrm{~mm}$. This was due to uneven distribution of load throughout the gear tooth flank where the stresses were shifted towards the edge of the gear. The result is similar to the analysis of Hassan [4] in which the stresses were extremely exaggerated and is called the corner 
contact as described by Houser [8]. When the coefficient of friction was varied from 0 to 0.3 , the contact stresses increased by $5-6 \%$ for different axial misalignment. The governing equation for the relationship between the normalized contact stress and the axial misalignment distance has been developed and is as shown in Equation 5 below:

$$
\begin{aligned}
& \frac{\sigma_{c \text { axl }}}{\sigma_{\text {ideal }}}=\left[-0.0358 f^{2}+0.0126 f-0.0054\right] d_{a x l}{ }^{2}+\left[0.224 f^{2}-0.0393 f+\right. \\
& 0.164] d_{a x l}+\left[-0.075 f^{2}+0.192 f+0.9882\right]
\end{aligned}
$$

where $f$ is the coefficient of friction and $d_{a x l}$ is the axial misalignment distance in $\mathrm{mm}$. Equation 5 is developed by finding a relationship to each plot of different friction values in Figure 8. Subsequently, the relationship between the constants of axial misalignment distance and friction is established. The output of the latter relationship is then incorporated in the former relationship. This is similar to obtaining the surface plot equation. Origin-pro graph plotting software was used for the process of developing the surface fitted equations.

On the other hand, the bending stresses were evaluated at the base of the tooth or the tooth fillet region of the gear using a stress probe. A stress probe was used to evaluate the maximum stress at a specific location. Figure 9 shows the graph of normalized bending stress $\left(\frac{\sigma_{\text {baxl }}}{\sigma_{\text {ideal }}}\right)$ against axial misalignment distance. The bending stress of the gear increases gradually as the axial misalignment distance increases. The maximum bending stress recorded without friction at $5 \mathrm{~mm}$ misalignment was $380.2 \mathrm{MPa}$ and the maximum percentage of increment due to axial misalignment was approximately $18.9 \%$. Furthermore, the bending stress values increase with the augmentation of coefficient of friction. When the friction was introduced, the bending stresses increased even more. When coefficient of friction of 0.3 was used, the bending stress for $5 \mathrm{~mm}$ misalignment case increased by $2.54 \%$ to $389 \mathrm{MPa}$. The governing equation for the relationship between the normalized bending stress and the axial misalignment distance has been developed in the similar manner as mentioned for Equation 5, i.e. surface plotting, and is as given in Equation 6 below:

$$
\begin{gathered}
\frac{\sigma_{\text {baxl }}}{\sigma_{\text {ideal }}}=\left[-0.0424 f^{2}+0.0127 f-0.00014\right] d_{\text {axl }}{ }^{2}+\left[0.175 f^{2}-\right. \\
0.042 f+0.0393] d_{\text {axl }}+\left[-0.025 f^{2}+0.0569 f+0.9965\right]
\end{gathered}
$$

where $f$ is the coefficient of friction and $d_{a x l}$ is the axial misalignment distance in $\mathrm{mm}$.

\section{Results for angular misalignment}

The variation of contact and bending stresses was studied for different angular misalignments which were parallel to the plane of action. The finite element method was performed and the contact and bending stresses were recorded for misalignment angles of $0.5^{\circ}, 1^{\circ}, 1.5^{\circ}$ and $2^{\circ}$. 


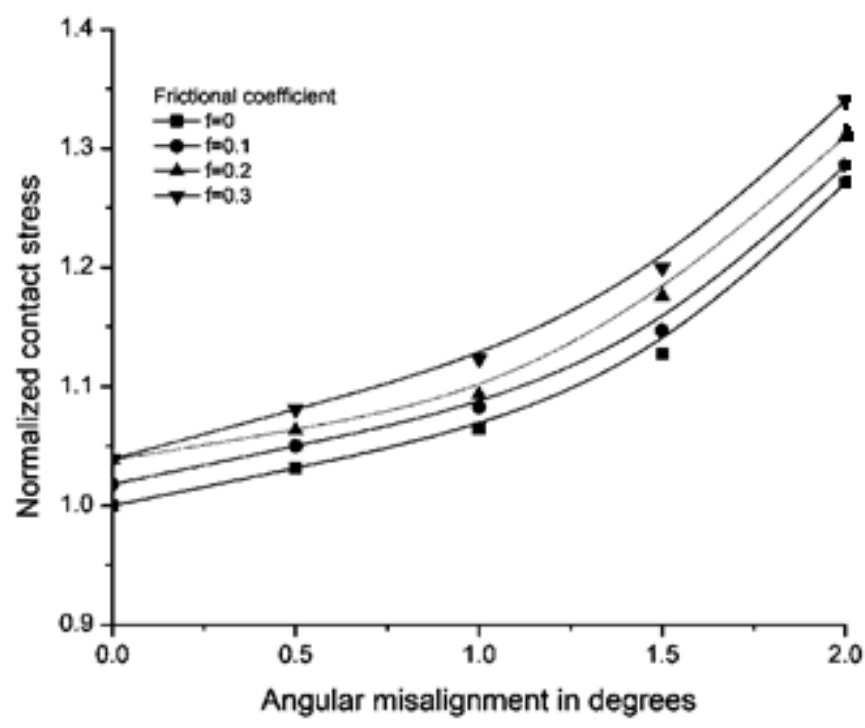

Figure 10. Maximum contact stress at the edge of gear tooth due to angular misalignment.

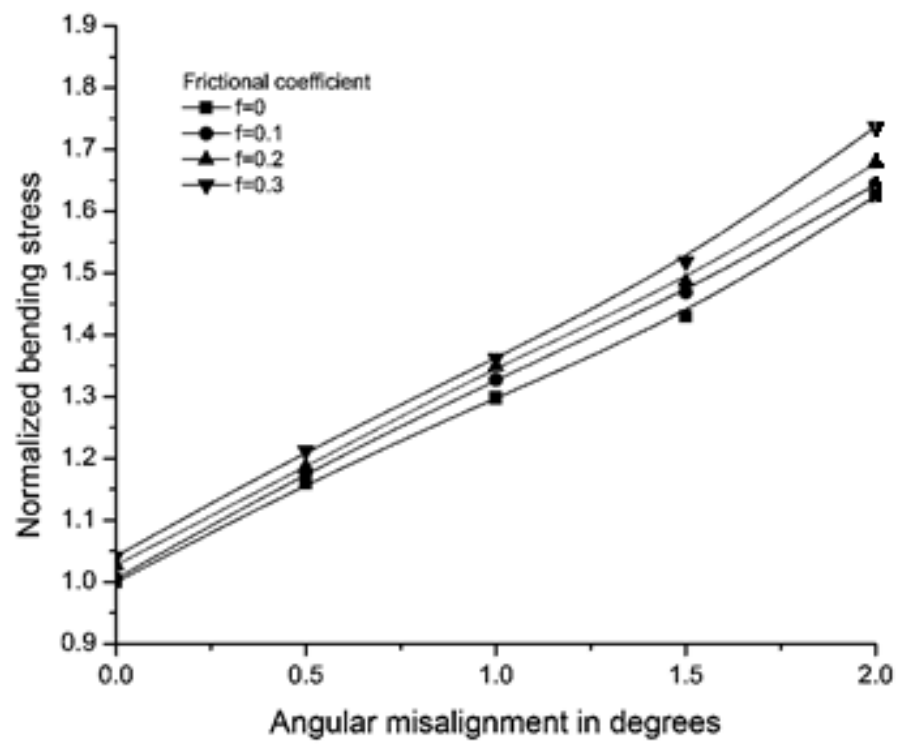

Figure 11. Maximum bending stress at the root of gear tooth due to angular misalignment.

Figure 10 shows the relationship between the normalized contact stress, $\left(\frac{\sigma_{\text {cang }}}{\sigma_{\text {ideal }}}\right)$ and misalignment angle. The maximum contact stress was determined at the contact point of the meshing gears. The contact stress values increased as the misalignment angles were increased. The maximum frictionless contact stress at misalignment angle of $2^{\circ}$ was 462.9 $\mathrm{MPa}$ which shows a percentage increase of $27 \%$. The contact stress rises by another $5.47 \%$ for a coefficient of friction of 0.3 . This result is consistent with the findings of 
Zheng Li and Ken Mao [17]. The degree of frictional effects on the contact stress depends on the frictional coefficient of contact surface and also the input torque. The surface fitting method is used again to develop Equation 7 and 8. The governing equation for the relationship between the normalized contact stress and the angular misalignment has been developed and is as shown in Equation 7 below:

$$
\begin{gathered}
\frac{\sigma_{\text {c ang }}}{\sigma_{\text {ideal }}}=\left[-0.21 f^{2}+0.0516 f+0.0712\right] d_{\text {ang }}{ }^{2}+\left[0.78 f^{2}-0.1566 f-\right. \\
0.0145] d_{\text {ang }}+\left[0.395 f^{2}+0.2511 f+1.006\right]
\end{gathered}
$$

where $f$ is the coefficient of friction and $d_{\text {ang }}$ is the angular misalignment in degree. Figure 11 shows the relationship between the normalized bending stresses, $\left(\frac{\sigma_{\text {b ang }}}{\sigma_{\text {ideal }}}\right)$ and misalignment angle. Based on the graph, there was a significant increase in the bending stresses when angular misalignment was introduced. The maximum bending stress recorded in the absence of friction for misalignment angle of $2^{\circ}$ was $519.6 \mathrm{MPa}$ representing an increment of $62.4 \%$ compared to no misalignment case. This is because when the gear is subjected to angular misalignment, the load distribution moves towards the edge of the gear tooth close to the tooth root. This uneven distribution of loading leads to higher stress concentrations on the gear tooth. The load concentration for bending stress is highest near the base of the tooth, similar to the work carried out in references $[13,20]$. When frictional coefficient of 0.3 was introduced, the bending stress increased from 519.6 $\mathrm{MPa}$ to $543.4 \mathrm{MPa}$ which gives an increment of $4.58 \%$. The governing equation for the relationship between the normalized bending stress and the angular misalignment has been developed and is as shown in Equation 8 below:

$$
\begin{aligned}
\frac{\sigma_{\text {bang }}}{\sigma_{\text {ideal }}=} & {\left[0.8802 f^{2}-0.2186 f+0.0168\right] d_{\text {ang }}{ }^{2}+\left[-1.6185 f^{2}-0.503 f+\right.} \\
& 0.2718] d_{\text {ang }}+\left[0.425 f^{2}+0.0215 f+1.0062\right]
\end{aligned}
$$

where $f$ is the coefficient of friction and $d_{a n g}$ is the angular misalignment in degree.

\section{CONCLUSION}

The relationship between the frictional contact and bending stresses with axial and angular misalignments was studied. The conclusions deduced from the study are:

1. The contact and bending stresses shifted towards the edge of the gear tooth in both types of misalignments (axial and angular). This was due to the load disturbance on the gear tooth because of misalignments.

2. The maximum contact and bending stresses for frictionless condition increased by $67.5 \%$ and $18.9 \%$, respectively, when axial misalignments were subjected. Hence, showing that the contact stresses are critical than bending stresses in the case of axial misalignment.

3. The maximum contact and bending stresses for frictionless condition increased by $27 \%$ and $62.4 \%$, respectively, for angular misalignments. Thus angular 
misalignments significantly affect the bending stresses when compared to contact stresses in gears.

4. The governing equations between normalized contact stress and misalignments (both axial and angular) and similar governing relations between normalized bending stress and misalignments were established.

5. The maximum contact and bending stresses increased when the coefficient of friction was increased from 0 to 0.3 . Hence, showing the considerable effect of friction on gear stresses.

\section{ACKNOWLEDGEMENTS}

The authors would like to thank Universiti Teknologi PETRONAS for providing the financial aid (URIF fund with cost center - 015 3AA B10), system support and facilities for the research work.

\section{REFERENCES}

[1] Lias MR, TVVLN R, Awang M, Khan MA. The stress distribution of gear tooth due to axial misalignment condition. Journal of Applied Sciences. 2012 Dec 1;12(23):2404-10.

[2] Guo Y, Lambert S, Wallen R, Errichello R, Keller J. Theoretical and experimental study on gear-coupling contact and loads considering misalignment, torque, and friction influences. Mechanism and Machine Theory. 2016 Apr 30;98:242-62.

[3] Ali SM, Mohammad OD. Load sharing on spur gear teeth and stress analysis when contact ratio changed. Eng. Tech. J. 2008;16:94-101.

[4] Hassan AR. Contact stress analysis of spur gear teeth pair. World Academy of Science, Engineering and Technology. 2009;Oct 20;58 (1):597-602.

[5] Li S, Anisetti A. A tribo-dynamic contact fatigue model for spur gear pairs. International Journal of Fatigue. 2017 May 1;98:81-91

[6] Patil SS, Karuppanan S, Atanasovska I. Contact stress evaluation of involute gear pairs, including the effects of friction and helix angle. Journal of Tribology. 2015 Oct 1;137(4):044501.

[7] Patil SS, Karuppanan S, Atanasovska I, Wahab AA. Contact stress analysis of helical gear pairs, including frictional coefficients. International Journal of Mechanical Sciences. 2014 Aug 1;85:205-11.

[8] Houser D, Harianto J, Talbot D. Gear mesh misalignment. Gear Solutions (June 2006). 2006 Jun:34-43.

[9] Ameen HA. Effect of shaft misalignment on the stresses distribution of spur gears. Eng. Tech. J.(2010);28:1321-1339.

[10] Bommisetty VS. Finite Element Analysis of Spur Gear Set (Doctoral dissertation, Cleveland State University).

[11] Juvinall RC, Marshek KM. Fundamentals of machine component design. New York: Wiley; 2000 Jan 5.

[12] Dolan TJ, Broghamer EL. A Photelastic study of stresses in gear tooth fillets. University of Illinois at Urbana Champaign, College of Engineering. Engineering Experiment Station. 1942.

[13] Prabhakaran S, Balaji DS, Joel C. Stress analysis and effect of misalignment in spur gear. International Journal of Applied Engineering Research. 2014;9(22):13061-71. 
[14] Farhan M, Karuppanan S, Patil SS. Frictional Contact Stress Analysis of Spur Gear by using Finite Element Method. In Applied Mechanics and Materials 2015 (Vol. 772, pp. 159-163). Trans Tech Publications.

[15] Refaat MH, Meguid SA. On the contact stress analysis of spur gears using variational inequalities. Computers \& structures. 1995 Dec 3;57(5):871-82.

[16] Patil S, Karuppanan S, Atanasovska I, Wahab AA. Frictional tooth contact analysis along line of action of a spur gear using Finite Element Method. Procedia Materials Science. 2014 Jan 1;5:1801-9.

[17] Li Z, Mao K. Frictional effects on gear tooth contact analysis. Advances in Tribology. 2013;2013.

[18] Hall A S, Holowenko A R, Laughlin H G. Machine Design.. Schum's outlines, McGraw Hill Education (India) Pvt. Ltd. Sie 2008. 18.1-18.4.

[19] Stefancu AI, Melenciuc SC, Budescu M. Finite element analysis of frictional contacts. Buletinul Institutului Politehnic din lasi. Sectia Constructii, Arhitectura. 2011 Jul 1;57(3):131.

[20] Rathore RK, Tiwari A. Bending Stress Analysis \& Optimization of Spur Gear. International Journal of Engineering. 2014 May;3(5). 